\title{
Factors related with colorectal and stomach cancer screening practice among disease- free lung cancer survivors in Korea
}

Sang Min Park ${ }^{1,2 \dagger}$, Jongmog Lee ${ }^{3 \dagger}$, Young Ae Kim ${ }^{4}$, Yoon Jung Chang ${ }^{4}$, Moon Soo Kim ${ }^{4}$, Young Mog Shim ${ }^{5}$, Jae III Zo ${ }^{5}$ and Young Ho Yun ${ }^{1,2,6^{*}}$

\begin{abstract}
Background: Lung cancer survivors are more likely to develop colorectal and stomach cancer than the general population. However, little is known about the current status of gastrointestinal cancer screening practices and related factors among lung cancer survivors.

Methods: We enrolled 829 disease-free lung cancer survivors $\geq 40$ years of age, who had been treated at two hospitals from 2001 to 2006. The patients completed a questionnaire that included stomach and colorectal cancer screening after lung cancer treatment, as well as other sociodemographic variables.

Results: Among lung cancer survivors, correlations with stomach and colorectal screening recommendations were 22.7 and $25.8 \%$, respectively. Of these, $40.7 \%$ reported receiving physician advice to screen for second primary cancer (SPC). Those who were recommended for further screening for other cancers were more likely to receive stomach cancer screening [adjusted odds ratios $(\mathrm{aOR})=1.63,95 \%$ confidence interval $(\mathrm{Cl}), 1.16-2.30$ ] and colorectal cancer screening $[\mathrm{aOR}=1.37,95 \% \mathrm{Cl}, 0.99-1.90]$. Less-educated lung cancer survivors were less likely to have stomach and colorectal cancer screenings.

Conclusions: Lack of a physician's advice for SPC screening and lower educational status had negative impact on the gastrointestinal cancer screening rates of lung cancer survivors.
\end{abstract}

Keywords: Colorectal cancer screening, Stomach cancer screening, Lung cancer survivor, Physician recommendation

\section{Background}

Although advanced stage lung cancer has a poor prognosis, [1] early stage lung cancer can be treated with surgical resection, resulting in an improved prognosis [2, 3]. Recently, the US Preventive Services Task Force (USPSTF) recommended annual screening for lung cancer, using low dose computed tomography (CT) for individuals at a high risk for this disorder [4]. Furthermore, the clinical practice of low dose CT scanning as an early detection tool, as well as

\footnotetext{
* Correspondence: lawyun@snu.ac.kr

${ }^{\dagger}$ Equal contributors

'Department of Biomedical Science, Seoul National University College of Medicine, 103 Daehak-ro, Jongno-gu, Seoul 110-799, Republic of Korea

${ }^{2}$ Department of Family Medicine, Seoul National University College of

Medicine, Seoul, Republic of Korea

Full list of author information is available at the end of the article
}

advances in cancer treatment, could lead to an increased number of lung cancer survivors $[3,4]$.

Previous studies have reported that lung cancer patients were at an increased risk for second primary cancers (SPCs) [5, 6]. For second primary gastrointestinal cancers, a recent study reported that early stage lung cancer patients had approximately a $40 \%$ increased risk of colorectal and stomach cancer than the general population [6]. The Global Burden of Disease Study in 2017 has demonstrated that colorectal cancer and stomach cancer are ranked within global top 5 cancers, [7] colorectal cancer screening and stomach cancer screening are introduced in several countries [8-10]. Cancer survivors were recommended to adhere routine age- and sex-appropriate cancer screening guideline in general population [11-13]. Especially, as colorectal cancer is 
the most common cancer, and stomach cancer remains the second common cancer in Korea, [14] continued surveillance program regarding gastrointestinal cancer screening for Korean lung cancer survivors will be needed. However, little is known about the gastrointestinal cancer screening practices in lung cancer survivors. The aim of our survey was to determine the patterns of screening for colorectal and stomach cancer screening and related factors in lung cancer survivors who were disease free in Korea. We hypothesized that not only low social-demographic status but also lack of physicians' advice for SPC screening or patients' misperception about their risk of SPC would have negative impacts on the gastrointestinal cancer screening behaviors in lung cancer survivors.

\section{Methods}

\section{Study participants}

We identified 2049 patients who had been treated for lung cancer in two hospitals in the Republic of Korea, between 2001 and 2006. We performed a cross-sectional survey of lung cancer survivors in 2007. Eligible subjects were contacted by telephone, and those who agreed to participate were surveyed with questionnaires at home or at the clinic. Lung cancer survivors who were treated with curative surgery and had no other history of cancer were eligible to participate. The institutional review board of the National Cancer Center, Korea reviewed and approved the protocol of our study. Details of the study design have been previously described [15].

\section{Definition of appropriate uptake of gastrointestinal cancer screening}

For stomach cancer screening, Korean National Cancer Screening Program (KNCSP) [8] recommended gastroscopy or double-contrast upper gastrointestinal series every 2 years for general population $\geq 40$ years of age, and the Japanese government introduced gastroscopy as a national screening program $[9,16]$. For early detection of colorectal cancer, annual FOBT was recommended for those $\geq 50$ years of age by the KNCSP [8] and by the USPSTF. The American Cancer Society (ACS) has recommended sigmoidoscopy every 5 years, a doublecontrast barium enema every 5 years, or a colonoscopy every 10 years $[10,17,18]$. However, colorectal screening guidelines for the general population could underestimate the actual needs of cancer survivors. One previous study reported that for cancer survivors aged 40-yearsold, colonoscopy every 5 years might be an economically feasible strategy [19]. As a baseline analysis of colorectal cancer screening, we considered all the above mentioned recommendations to be compliant with colorectal screening among lung cancer survivors $\geq 40$ years of age. We also performed sensitivity analysis with subject $\geq 50$ years of age, using the above cancer screening recommendations.

To assess the practices of stomach and colorectal cancer screening after cancer treatment, lung cancer survivors were asked the following questions (Additional file 1): 1) "When did you receive a gastroscopy or double-contrast upper gastrointestinal series recently?" with responses of "no," " $\leq 2$ years ago," "2-5 years ago," and ">5 years ago"; 2) "What kind of colorectal cancer screening test did you receive?" with responses of "no," "fecal occult blood test (FOBT)," "double-contrast barium enema," "sigmoidoscopy," and "colonoscopy"; and 3) "If you receive a colorectal cancer screening, when did you receive the last colorectal cancer screening test?" with responses of "<1 year ago," " $1-5$ years ago," "5-10 years ago," and ">10 years ago."

\section{Independent variables}

Lung cancer survivors were asked to approximate their risk of SPC compared with cancer risk in general population, with the responses being lower, similar, or higher. The survey also included question about receiving a physicians' recommendation to screen for SPC after lung cancer treatment. In addition, participants were asked to answer questions about age, highest educational attainment, ethnicity, income, health behavior (physical activity, smoking, alcohol consumption, height and weight), and health-related quality of life (the European Organization for Research and Treatment of Cancer Quality of Life Questionnaire Core-30 item and lung cancer module, Hospital Anxiety and Depression Scale and Posttraumatic Growth Inventory) through our systematically organized questionnaire. From the hospital cancer registries, we gathered information about clinical characteristics such as ages at cancer diagnosis, tumor stage, type of surgery, history of chemotherapy or radiotherapy, and recurrence.

\section{Statistical analysis}

Descriptive statistics were reported for each response. Among subjects, those who received gastroscopy or double-contrast upper gastrointestinal series within 2 years were defined as lung cancer survivors with appropriate stomach cancer screening [8]. Lung cancer survivors who received FOBT within 1 year, a doublecontrast barium enema within 5 years, sigmoidoscopy within 5 years, or colonoscopy within 10 years were defined as receiving appropriate colorectal cancer screening $[10,17,18]$. We then calculated the occurrences of lung cancer survivors who had second gastrointestinal cancer screening according to these guidelines.

Adjusted odds ratios were determined by logistic regression analysis, main independent variable being physicians' advice for SPC screening, perception of 
second cancer risk, highest educational attainment, and family income adjusted for age, stage, marital status, smoking status, and alcohol consumption. We also performed sensitivity analysis with lung cancer survivors $\geq 50$ years of age. All statistical analyses were two-sided and performed using STATA 10.0 software (Stata Corp., College Station, TX, USA). The significance level was set at $P<0.05$.

\section{Results}

Among the potentially eligible population, 126 (6.1\%) had died, 290 (14.2\%) could not be contacted in spite of multiple attempts. Excluded from this study were patients whose cancer had recurred at the time of the survey. All participants provided written informed consent. Of the 1633 contacted patients, 727 (35.5\%) refused to participate, and 906 (44.2\%) consented to participate. Among the respondents, 76 patients had cancer which had recurred, or were receiving cancer therapy at the time. One subject $<40$ years of age was excluded. The analysis included 829 lung cancer survivors $\geq 40$ years of age.

The mean age of 829 lung cancer survivors was 62.9 years (40-78 years). Of these, $44.2 \%$ had no more than a 6th grade education, and $63.1 \%$ was diagnosed as stage I lung cancer. Among disease-free lung cancer survivors, $40.7 \%$ reported receiving physician advice to screen for other cancers. About one out of ten reported a perception that they had a lower risk of other cancers than the general population, and $60.1 \%$ believed that they had a higher risk of other cancers than general population (Table 1). When we compared the characteristics of the participants and non-participants among1633 contacted patients, responders were more likely to be men and to live in metropolitan areas than non-participants (Additional file 2: Table S1).

The proportions for receiving appropriate stomach cancer screening and colorectal cancer screening were 22.7 and $26.1 \%$, respectively (Fig. 1). Both male and female lung cancer survivors showed similar trends of SPC cancer screening.

\section{Factors related to the uptake of stomach cancer screening for lung cancer survivors}

Lung cancer survivors who recalled being informed about the need for SPC screening were more likely to have stomach cancer screening in multivariate-adjusted analysis [adjusted $\mathrm{OR}(\mathrm{aOR})=1.63,95 \% \mathrm{CI}, 1.16-2.30$ ], and these associations were greater among male patients (Table 2). When we assessed compliance of stomach cancer screening practices by monthly household income and perception of SPC risk, there were no significant differences among the groups. Lung cancer survivors with the most education ( $\geq 12$ years) were more likely to have stomach cancer screening
Table 1 Demographic and clinical characteristics of disease-free lung cancer survivors

\begin{tabular}{|c|c|c|}
\hline Characteristics & $\mathrm{N}$ & $\%$ \\
\hline Age, years (mean) & (62.9) & \\
\hline $40-49$ & 58 & 7.0 \\
\hline $50-64$ & 379 & 45.7 \\
\hline$\geq 65$ & 393 & 47.3 \\
\hline \multicolumn{3}{|l|}{ Gender } \\
\hline Male & 637 & 76.8 \\
\hline Female & 193 & 23.2 \\
\hline \multicolumn{3}{|l|}{ Marital Status } \\
\hline Married & 764 & 90.7 \\
\hline Unmarried, divorced, or bereaved & 66 & 9.3 \\
\hline \multicolumn{3}{|l|}{ Level of Education } \\
\hline$\leq 6$ years & 229 & 44.2 \\
\hline $7-11$ years & 389 & 28.6 \\
\hline$\geq 12$ years & 210 & 27.2 \\
\hline \multicolumn{3}{|l|}{ Monthly household income, \$(US) } \\
\hline$\geq 3000$ & 225 & 27.2 \\
\hline 1000-2999 & 363 & 43.8 \\
\hline$<1000$ & 240 & 29.0 \\
\hline \multicolumn{3}{|l|}{ Stage } \\
\hline । & 519 & 63.1 \\
\hline$\|$ & 173 & 21.0 \\
\hline III & 131 & 15.0 \\
\hline \multicolumn{3}{|c|}{ Receiving physician advice to screen for SPC } \\
\hline Yes & 337 & 40.7 \\
\hline No & 491 & 59.3 \\
\hline \multicolumn{3}{|l|}{ Self-perception of the SPC risk } \\
\hline Lower than the general population & 77 & 9.3 \\
\hline Same as the general population & 253 & 30.6 \\
\hline Higher than the general population & 496 & 60.1 \\
\hline
\end{tabular}

SPC second primary cancer

(aOR $=1.72,95 \% \mathrm{CI}, 1.00-2.96)$, especially for male patients (aOR 1.87, 95\% CI, 1.00-3.51). Multivariate analysis of patients $\geq 50$ years of age showed associations between the above factors with uptake of stomach cancer screening that were similar to those of patients $\geq 40$ years of age.

\section{Factors related to the uptake of colorectal cancer screening for lung cancer survivors}

Participant's reporting to receive a physicians' advice to screen for other cancers was positively associated with receiving colorectal cancer screening in both ageadjusted analysis $(\mathrm{aOR}=1.52$; 95\% CI, 1.09-2.12) and multivariate analysis $(\mathrm{aOR}=1.37,95 \% \mathrm{CI}, 0.99-1.91$; Table 3). Self-perception of SPC risk was not 


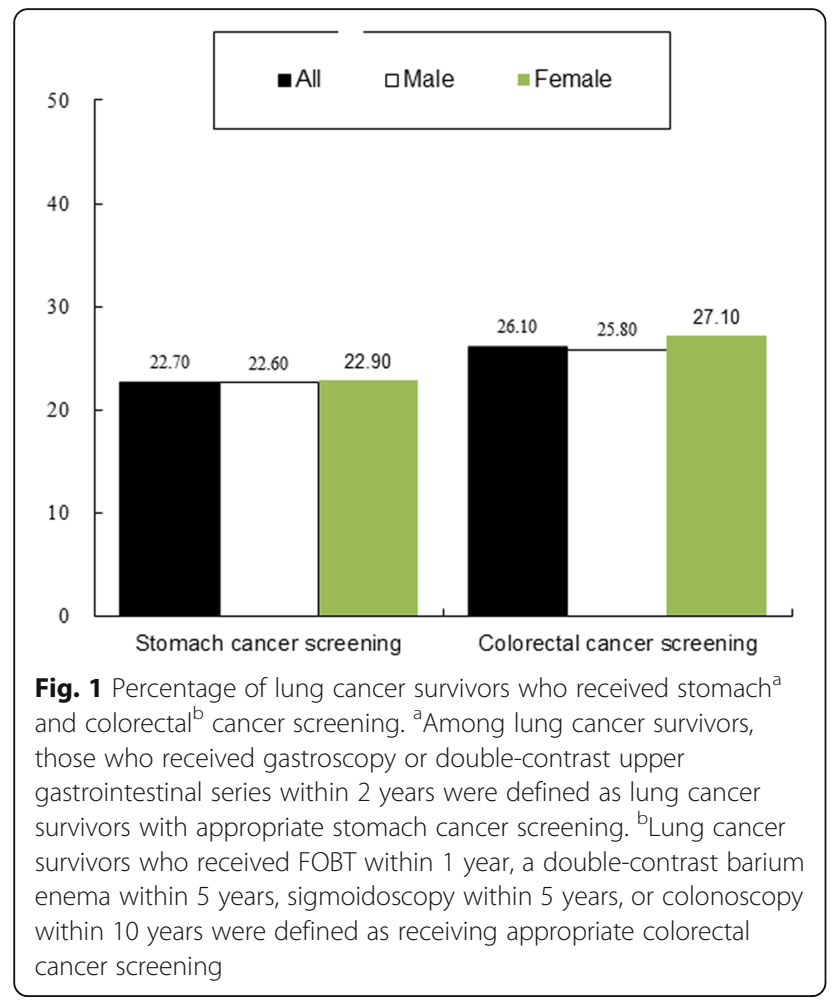

significantly associated with colorectal screening practices. Less-educated patients were less likely to have colorectal cancer screening $(\mathrm{aOR}=1.76,95 \% \mathrm{CI}$, 1.05-2.96). Family income was also significantly associated with colorectal cancer screening compliance among female lung cancer survivors. Compared with family income less than $\$ 1000 /$ month, female lung cancer survivors with a higher income $(\geq \$ 3000 /$ month) were more likely to undergo a colorectal cancer screening $(\mathrm{aOR}=5.09,95 \% \mathrm{CI}, 1.28-20.14)$.

When we performed a sensitivity analysis with subjects $\geq 50$ years of age, male lung cancer survivors who received a physicians' advice of screening for second cancers were more likely to have a colorectal cancer screening $(\mathrm{aOR}=1.48,95 \% \mathrm{CI}, 1.00-2.18)$.

\section{Discussion}

Our study showed that colorectal and gastric cancer screening practices among lung cancer survivors was less than optimal. In addition, half of these patients did not recall receiving advice from their physicians about SPC screening. Lack of a physicians' advice for SPC screening and lower educational status might have negative impact on the gastrointestinal cancer screening rates of lung cancer survivors.

Because lung cancer survivors have an increased risk of colorectal and stomach cancer development, $[5,6]$

Table 2 Factors related to the uptake of stomach cancer screening ${ }^{\text {a }}$ for lung cancer survivors

\begin{tabular}{|c|c|c|c|c|c|c|c|c|c|}
\hline \multirow[t]{2}{*}{ Variables } & \multicolumn{3}{|c|}{ All patients $(N=829)$} & \multicolumn{3}{|c|}{ Male patients $(N=641)$} & \multicolumn{3}{|c|}{ Female patients $(N=188)$} \\
\hline & $\%$ & $\begin{array}{l}\text { Age-adjusted } \\
\text { OR (95\% CI) }\end{array}$ & $\begin{array}{l}\text { Multivariate } \\
\operatorname{OR}^{b}(95 \% \mathrm{Cl})\end{array}$ & $\%$ & $\begin{array}{l}\text { Age-adjusted } \\
\text { OR (95\% CI) }\end{array}$ & $\begin{array}{l}\text { Multivariate } \\
\mathrm{OR}^{\mathrm{b}}(95 \% \mathrm{Cl})\end{array}$ & $\%$ & $\begin{array}{l}\text { Age-adjusted } \\
\text { OR ( } 95 \% \text { CI) }\end{array}$ & $\begin{array}{l}\text { Multivariate } O R^{b} \\
(95 \% \mathrm{Cl})\end{array}$ \\
\hline \multicolumn{10}{|c|}{ Receiving physician advice to screen for SPC } \\
\hline No & 19.8 & 1.0 & 1.0 & 19.5 & 1.0 & 1.0 & 20.8 & 1.0 & 1.0 \\
\hline Yes & 26.7 & $1.52(1.09-2.11)$ & $1.61(1.14-2.26)$ & 27.4 & $1.59(1.09-2.32)$ & $1.73(1.17-2.56)$ & 24.7 & $1.32(0.66-2.63)$ & $1.30(0.61-2.80)$ \\
\hline \multicolumn{10}{|c|}{ Perceived risk of SPC in lung cancer survivors } \\
\hline $\begin{array}{l}\text { Lower than general } \\
\text { population }(\mathrm{GP})\end{array}$ & 20.8 & 1.0 & 1.0 & 22.9 & 1.0 & 1.0 & 12.5 & 1.0 & 1.0 \\
\hline $\begin{array}{l}\text { Same or higher } \\
\text { than GP }\end{array}$ & 22.6 & $1.07(0.60-1.91)$ & $1.16(0.63-2.13)$ & 22.4 & $0.95(0.51-1.79)$ & $0.97(0.50-1.88)$ & 23.0 & $1.89(0.40-8.92)$ & $2.34(0.44-12.43)$ \\
\hline \multicolumn{10}{|c|}{ Monthly household income, (\$US) } \\
\hline$<1000$ & 19.6 & 1.0 & 1.0 & 18.9 & 1.0 & 1.0 & 22.0 & 1.0 & 1.0 \\
\hline 1000-2999 & 21.8 & $1.11(0.73-1.67)$ & $1.03(0.66-1.59)$ & 22.5 & $1.20(0.75-1.92)$ & $1.06(0.64-1.73)$ & 19.5 & $0.79(0.31-1.97)$ & $1.10(0.33-3.05)$ \\
\hline$\geq 3000$ & 27.4 & $1.44(0.91-2.23)$ & $1.48(0.94-2.32)$ & 27.2 & $1.50(0.88-2.56)$ & $1.20(0.66-1.71)$ & 28.1 & $1.24(0.48-3.21)$ & $1.34(0.37-4.95)$ \\
\hline \multicolumn{10}{|l|}{ Education } \\
\hline$\leq 6$ years & 17.5 & 1.0 & 1.0 & 14.6 & 1.0 & 1.0 & 24.6 & 1.0 & 1.0 \\
\hline $7-11$ years & 22.7 & $1.33(0.86-2.06)$ & $1.40(0.88-2.22)$ & 24.7 & $1.88(1.11-3.19)$ & $1.93(1.11-3.35)$ & 15.9 & $0.51(0.22-1.20)$ & $0.46(0.17-1.24)$ \\
\hline$\geq 12$ years & 28.6 & $1.78(1.10-2.87)$ & $1.72(1.00-2.96)$ & 26.9 & $2.09(1.18-3.72)$ & $1.87(1.00-3.51)$ & 35.9 & $1.43(0.56-3.64)$ & $1.34(0.40-4.48)$ \\
\hline
\end{tabular}

OR odds ratio, $\mathrm{Cl}$ confidence interval, SPC second primary cancer

${ }^{a}$ Subjects who received gastroscopy or double-contrast upper gastrointestinal series within 2 years were defined as lung cancer survivors with appropriate stomach cancer screening

${ }^{\mathrm{b}}$ Adjusted for age, stage, marital status, education, family income status, smoking status, alcohol consumption, receiving recommendation for other cancer screening, and the perception of secondary cancer risks 
Table 3 Factors related to the uptake of colorectal cancer screening ${ }^{a}$ for lung cancer survivors

\begin{tabular}{|c|c|c|c|c|c|c|c|c|c|}
\hline \multirow[t]{2}{*}{ Variables } & \multicolumn{3}{|c|}{ All patients $(N=829)$} & \multicolumn{3}{|c|}{ Male patients $(N=641)$} & \multicolumn{3}{|c|}{ Female patients $(N=188)$} \\
\hline & $\%$ & $\begin{array}{l}\text { Age-adjusted } \\
\text { OR }(95 \% \mathrm{Cl})\end{array}$ & $\begin{array}{l}\text { Multivariate } \\
\operatorname{OR}^{\mathrm{b}}(95 \% \mathrm{Cl})\end{array}$ & $\%$ & $\begin{array}{l}\text { Age-adjusted } \\
\text { OR }(95 \% \mathrm{Cl})\end{array}$ & $\begin{array}{l}\text { Multivariate } \\
\text { OR }^{\mathrm{b}}(95 \% \mathrm{Cl})\end{array}$ & $\%$ & $\begin{array}{l}\text { Age-adjusted } \\
\text { OR }(95 \% \mathrm{Cl})\end{array}$ & $\begin{array}{l}\text { Multivariate } \mathrm{OR}^{\mathrm{b}} \\
(95 \% \mathrm{Cl})\end{array}$ \\
\hline \multicolumn{10}{|c|}{ Receiving physician advice to screen for SPC } \\
\hline No & 23.3 & 1.0 & 1.0 & 22.9 & 1.0 & 1.0 & 25.0 & 1.0 & 1.0 \\
\hline Yes & 29.0 & $1.52(1.09-2.12)$ & $1.37(0.99-1.91)$ & 29.2 & $1.38(0.96-1.99)$ & $1.46(1.00-2.12)$ & 28.2 & $1.30(0.68-2.48)$ & $1.14(0.53-2.48)$ \\
\hline \multicolumn{10}{|c|}{ Perceived risk of SPC in lung cancer survivors } \\
\hline $\begin{array}{l}\text { Lower than general } \\
\text { population (GP) }\end{array}$ & 21.6 & 1.0 & 1.0 & 22.0 & 1.0 & 1.0 & 20.0 & 1.0 & 1.0 \\
\hline $\begin{array}{l}\text { Same or higher } \\
\text { than GP }\end{array}$ & 25.9 & $1.07(0.60-1.91)$ & $1.14(0.65-2.03)$ & 25.7 & $1.16(0.62-2.16)$ & $1.13(0.59-2.15)$ & 26.6 & $1.08(0.32-3.62)$ & $1.37(0.33-5.63)$ \\
\hline \multicolumn{10}{|c|}{ Monthly household income, \$(US) } \\
\hline$<1000$ & 24.2 & 1.0 & 1.0 & 24.6 & 1.0 & 1.0 & 22.5 & 1.0 & 1.0 \\
\hline 1000-2999 & 21.6 & $1.96(0.73-1.67)$ & $0.73(0.48-1.12)$ & 22.5 & $0.85(0.55-1.32)$ & $0.68(0.43-1.10)$ & 17.9 & $0.88(0.44-4.48)$ & $1.51(0.47-4.88)$ \\
\hline$\geq 3000$ & 34.5 & $1.45(0.91-2.30)$ & $1.22(0.74-2.02)$ & 32.2 & $1.47(0.89-2.41)$ & $1.02(0.58-1.82)$ & 40.7 & $2.98(1.18-7.53)$ & $5.09(1.28-20.14)$ \\
\hline \multicolumn{10}{|l|}{ Education } \\
\hline$\leq 6$ years & 20.8 & 1.0 & 1.0 & 17.8 & 1.0 & 1.0 & 28.6 & 1.0 & 1.0 \\
\hline $7-11$ years & 25.3 & $1.33(0.86-2.05)$ & $1.34(0.87-2.09)$ & 27.4 & $1.73(1.05-2.84)$ & $1.91(1.13-3.23)$ & 17.7 & $0.56(0.25-1.27)$ & $0.34(0.12-0.94)$ \\
\hline$\geq 12$ years & 33.2 & $1.78(1.11-2.88)$ & $1.76(1.05-2.96)$ & 30.3 & $2.14(1.25-3.68)$ & $1.87(1.02-3.41)$ & 48.3 & $2.75(1.12-6.78)$ & $1.35(0.40-4.48)$ \\
\hline
\end{tabular}

$O R$ odds ratio, $\mathrm{Cl}$ confidence interval, SPC second primary cancer

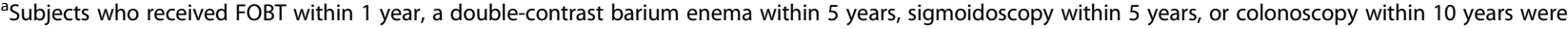
defined as receiving appropriate colorectal cancer screening

${ }^{\mathrm{b}}$ Adjusted for age, stage, marital status, education, family income status, smoking status, alcohol consumption, receiving recommendation for other cancer screening, and perception of secondary cancer risks

following the recommendations of gastrointestinal cancer screening for the average risk population should be needed at a minimum. However, our study showed that less than $30 \%$ of disease-free lung cancer survivors adhered to these colorectal and stomach screening recommendations. Several previous studies [20, 21] and one recent meta-analysis [22] reported that many cancer survivors did not receive screening tests recommended for the detection of SPCs, although cancer survivors received more frequent screening for cancers than noncancer controls. These findings emphasized the need to identify effective methods to increase cancer screening practices for cancer survivors. Several interventions, such as reminders, small media, and face-to-face education have been reported to increase screening rates in general population [23]. However, little is known about whether these interventions of increasing appropriate knowledge could lead to increased SPC screening among cancer survivors. Furthermore, an interventional trial using educational materials to increase knowledge about SPC screening reported no increase in actual cancer screening for cancer survivors [24].

The present study showed that a lack of recommendation for SPC screening from physicians might have a negative impact on the colorectal and stomach cancer screening behaviors among lung cancer survivors.
Similarly, a previous study reported that cervical cancer survivors who received, to whom their health care providers had recommended other cancer screening, were more likely to receive breast cancer screening [25]. After experiencing cancer, survivors usually have high levels of trust in their physicians, $[26,27]$ and physicians' advice for screening might provide good opportunities to improve SPC screening behaviors.

Only $40.7 \%$ of disease-free lung cancer survivors, however, recalled being informed about the need for SPC screening or referred for such tests. Together with the results of previous studies, our results suggests that more information and training regarding appropriate cancer screening guidelines for cancer survivors will be needed for health care providers. Because there were few guidelines regarding such specific SPC screening, a feasible step should be started with increasing cancer survivors' compliance to cancer screening guidelines for the general population. If physicians' recommendation for SPC screening would be incorporated in the survivorship care plan, it might foster physician communication and shared care in monitoring SPC screening for cancer survivors.

We also found educational disparities in stomach and colorectal cancer screening among lung cancer survivors, and found income disparities in colorectal cancer 
screening among female subjects. Although several studies have reported educational and income disparities in cancer screening practices among the general population, [28, 29] little is known about these disparities among cancer survivors. In order to provide equal access to SPC screening services for cancer survivors, further collaborative efforts by policy makers, third party payers, and healthcare providers are needed. Several previous studied have suggested that educational disparity on receipt of cancer screening might be mediated by the role of health literacy [30, 31]. Further study for loweducated cancer patients will be needed to increase appropriate knowledge and attitude for SPC screening during or after the cancer treatment periods. Furthermore, because cancer survivors are more financially vulnerable, $[32,33]$ decreasing economic barrier for SPC screening should be considered.

Our study had several limitations. First, we used selfreported survey to assess the cancer screening compliance and physicians' advice for SPC screening, which were not confirmed by medical record reviews or claims. Second, the response rate was only $44.2 \%$. As participants could have been more likely to have preventive health behaviors than non-participants, our estimates of SPC screening practices among lung cancer survivors might therefore have been overestimated. Third, our study population consisted of Korean lung cancer survivors and stomach cancer screening is not recommended in western countries, which may limit the generalizability of our results. Although recent study has demonstrated that those who received an upper endoscopy were less likely to die from stomach cancer within the Korean national cancer screening program, [34] and cancer survivors were usually recommended to receive routine cancer screening guideline which is recommended in general population, [11-13] further evidences will be needed among other ethnicities.

\section{Conclusion}

The present study showed that only a quarter of lung cancer survivors included were meeting existing guidelines for second primary cancer screening, particularly gastric and colorectal cancer. Physician must more proactive in communicating the need for screening and referring patients for such screening tests. In addition, further public policy will be needed to decrease educational disparities in SPC screening practices.

\section{Additional files}

Additional file 1: Questionnaires about uptake of gastrointestinal cancer screening among lung cancer survivors. (DOCX 14 kb)

Additional file 2: Table S1. Characteristics of the participants and non-participants. (DOC 27 kb)
Abbreviations

aOR: Adjusted odds ratios; Cl: Confidence interval; SPC: Second primary cancer

\section{Acknowledgements}

N/A

\section{Funding}

This work was supported by the National Cancer Center Grant 0710410 and grants from the National R\&D Program for Cancer Control, Ministry of Health \& Welfare, Republic of Korea (1320330).

The design of the study and collection, analysis, and interpretation of data and in writing the manuscript are independent from the funding sources.

\section{Availability of data and materials}

The dataset supporting the conclusions of this article is available at request from the corresponding author.

\section{Authors' contributions}

SMP, $J$ and YHY made substantial contribution to analysis and interpretation of data, drafting and submission of the manuscript. JL, MSK, MYS, JAZ contributed to design of the study, acquisition of the data and drafting of the manuscript. SMP and YAK contributed to the design of the study and performed the statistical analysis. YHY conceived the study, participated in its design and coordination and contributed to interpretation of the data and drafting of the manuscript. YAK and YJC participated in the design of the study, contributed to the interpretation of the data. All authors read and approved the final manuscript.

Ethics approval and consent to participate

The institutional review board of the National Cancer Center, Korea reviewed and approved the protocol of our study. All participants provided written informed consent.

\section{Consent for publication}

Not applicable.

\section{Competing interests}

The authors declare that they have no competing interests.

\section{Publisher's Note}

Springer Nature remains neutral with regard to jurisdictional claims in published maps and institutional affiliations.

\section{Author details}

${ }^{1}$ Department of Biomedical Science, Seoul National University College of Medicine, 103 Daehak-ro, Jongno-gu, Seoul 110-799, Republic of Korea. ${ }^{2}$ Department of Family Medicine, Seoul National University College of Medicine, Seoul, Republic of Korea. ${ }^{3}$ Center for Lung Cancer, National Cancer Center, Goyang, Republic of Korea. ${ }^{4}$ National Cancer Control Institute, National Cancer Center, Goyang, Republic of Korea. ${ }^{5}$ Lung and Esophageal Cancer Center, Samsung Comprehensive Cancer Center, Samsung Medical Center, Seoul, Republic of Korea. ${ }^{6}$ Cancer Research Institute, Seoul National University College of Medicine, Seoul, Republic of Korea.

Received: 6 April 2016 Accepted: 22 August 2017

Published online: 30 August 2017

\section{References}

1. Visbal AL, Williams BA, Nichols FC 3rd, Marks RS, Jett JR, Aubry MC, Edell ES, Wampfler JA, Molina JR, Yang P. Gender differences in non-small-cell lung cancer survival: an analysis of 4,618 patients diagnosed between 1997 and 2002. Ann Thorac Surg. 2004;78(1):209-15. discussion 215

2. Sugimura $H$, Yang P. Long-term survivorship in lung cancer: a review. Chest. 2006;129(4):1088-97.

3. Manser R, Wright G, Hart D, Byrnes G, Campbell DA. Surgery for early stage non-small cell lung cancer. Cochrane Database Syst Rev. 2005;1:CD004699.

4. Moyer VA, Force USPST. Screening for lung cancer: U.S. preventive services task force recommendation statement. Ann Intern Med. 2014;160(5):330-8.

5. Chuang SC, Scelo G, Lee YC, Friis S, Pukkala E, Brewster DH, Hemminki K, Tracey E, Weiderpass E, Tamaro S, et al. Risks of second primary cancer 
among patients with major histological types of lung cancers in both men and women. Br J Cancer. 2010;102(7):1190-5.

6. Surapaneni R, Singh P, Rajagopalan K, Hageboutros A. Stage I lung cancer survivorship: risk of second malignancies and need for individualized care plan. J Thorac Oncol. 2012;7(8):1252-6.

7. Global Burden of Disease Cancer C, Fitzmaurice C, Allen C, Barber RM, Barregard L, Bhutta ZA, Brenner H, Dicker DJ, Chimed-Orchir O, Dandona R, et al. Global, regional, and National Cancer Incidence, mortality, years of life lost, years lived with disability, and disability-adjusted life-years for 32 cancer groups, 1990 to 2015: a systematic analysis for the global burden of disease study. JAMA Oncol. 2017;3(4):524-48.

8. Ministry of Health and Welfare K. National cancer screening programmes guidelines. Seoul: Ministry of Health and Welfare; 2006.

9. Tashiro A, Sano M, Kinameri K, Fujita K, Takeuchi Y. Comparing mass screening techniques for gastric cancer in Japan. World J Gastroenterol. 2006;12(30):4873-4.

10. Force USPST. Screening for colorectal cancer: U.S. preventive services task force recommendation statement. Ann Intern Med. 2008;149(9):627-37.

11. Resnick MJ, Lacchetti C, Bergman J, Hauke RJ, Hoffman KE, Kungel TM Morgans AK, Penson DF. Prostate cancer survivorship care guideline: American Society of Clinical Oncology clinical practice guideline endorsement. J Clin Oncol. 2015;33(9):1078-85.

12. Nekhlyudov L, Lacchetti C, Davis NB, Garvey TQ, Goldstein DP, Nunnink JC, Ninfea JIR, Salner AL, Salz T, Siu LL. Head and neck cancer survivorship care guideline: American Society of Clinical Oncology clinical practice guideline endorsement of the American Cancer Society guideline. J Clin Oncol. 2017; 35(14):1606-21.

13. El-Shami K, Oeffinger KC, Erb NL, Willis A, Bretsch JK, Pratt-Chapman ML, Cannady RS, Wong SL, Rose J, Barbour AL, et al. American Cancer Society colorectal cancer survivorship care guidelines. CA Cancer J Clin. 2015;65(6): 428-55

14. Jung KW, Won YJ, Oh CM, Kong HJ, Lee DH, Lee KH. Prediction of cancer incidence and mortality in Korea, 2017. Cancer Res Treat. 2017;49(2):306-12.

15. Yun YH, Kim YA, Min YH, Chang YJ, Lee J, Kim MS, Lee HS, Kim J, Choi YS, Shim YM, et al. Health-related quality of life in disease-free survivors of surgically treated lung cancer compared with the general population. Ann Surg. 2012;255(5):1000-7.

16. Hamashima C. Benefits and harms of endoscopic screening for gastric cancer. World J Gastroenterol. 2016;22(28):6385-92.

17. Smith RA, Manassaram-Baptiste D, Brooks D, Cokkinides V, Doroshenk M, Saslow D, Wender RC, Brawley OW. Cancer screening in the United States, 2014: a review of current American Cancer Society guidelines and current issues in cancer screening. CA Cancer J Clin. 2014;64(1):30-51.

18. Levin B, Lieberman DA, McFarland B, Smith RA, Brooks D, Andrews KS, Dash C, Giardiello FM, Glick S, Levin TR, et al. Screening and surveillance for the early detection of colorectal cancer and adenomatous polyps, 2008: a joint guideline from the American Cancer Society, the US multi-society task force on colorectal cancer, and the American College of Radiology. CA Cancer J Clin. 2008;58(3):130-60

19. Park SM, Kim SY, Earle CC, Jeong SY, Yun YH. What is the most costeffective strategy to screen for second primary colorectal cancers in male cancer survivors in Korea? World J Gastroenterol. 2009;15(25):3153-60.

20. Earle CC, Burstein HJ, Winer EP, Weeks JC. Quality of non-breast cance health maintenance among elderly breast cancer survivors. J Clin Oncol. 2003;21(8):1447-51.

21. Nathan PC, Ness KK, Mahoney MC, Li Z, Hudson MM, Ford JS, Landier W, Stovall M, Armstrong GT, Henderson TO, et al. Screening and surveillance for second malignant neoplasms in adult survivors of childhood cancer: a report from the childhood cancer survivor study. Ann Intern Med. 2010; 153(7):442-51.

22. Corkum M, Hayden JA, Kephart G, Urquhart R, Schlievert C, Porter G. Screening for new primary cancers in cancer survivors compared to noncancer controls: a systematic review and meta-analysis. J Cancer Surviv. 2013;7(3):455-63.

23. Brouwers MC, De Vito C, Bahirathan L, Carol A, Carroll JC, Cotterchio M, Dobbins $\mathrm{M}$, Lent $\mathrm{B}$, Levitt $\mathrm{C}$, Lewis $\mathrm{N}$, et al. What implementation interventions increase cancer screening rates? A systematic review. Implement Sci. 2011;6:111.

24. Shin DW, Cho J, Kim YW, Oh JH, Kim SW, Chung KW, Lee WY, Lee JE, Guallar E, Lee WC. Efficacy of an educational material on second primary cancer screening practice for cancer survivors: a randomized controlled trial. PLoS One. 2012;7(3):e33238.

25. Park SM, Park CT, Park SY, Bae DS, Nam JH, Cho CH, Lee JM, Earle CC, Yun $\mathrm{YH}$. Factors related to second cancer screening practice in disease-free cervical cancer survivors. Cancer Causes Control. 2009;20(9):1697-703.

26. Hillen MA, Koning CC, Wilmink JW, Klinkenbijl JH, Eddes EH, Kallimanis-King $\mathrm{BL}$, de Haes JC, Smets EM. Assessing cancer patients' trust in their oncologist: development and validation of the Trust in Oncologist Scale (TiOS). Support Care Cancer. 2012;20(8):1787-95.

27. Hillen MA, Postma RM, Verdam MG, Smets EM. Development and validation of an abbreviated version of the Trust in Oncologist Scale-the Trust in oncologist scale-short form (TiOS-SF). Support Care Cancer. 2017;25(3):855-61.

28. Ross JS, Bradley EH, Busch SH. Use of health care services by lower-income and higher-income uninsured adults. JAMA. 2006;295(17):2027-36.

29. Lee K, Lim HT, Hwang SS, Chae DW, Park SM. Socio-economic disparities in behavioural risk factors for cancer and use of cancer screening services in Korean adults aged 30 years and older: the third Korean National Health and nutrition examination survey, 2005 (KNHANES III). Public Health. 2010; 124(12):698-704.

30. Bennett IM, Chen J, Soroui JS, White S. The contribution of health literacy to disparities in self-rated health status and preventive health behaviors in older adults. Ann Fam Med. 2009;7(3):204-11.

31. Mantwill S, Monestel-Umana S, Schulz PJ. The relationship between health literacy and health disparities: a systematic review. PLoS One. 2015;10(12): e0145455.

32. Park JH, Park EC, Park JH, Kim SG, Lee SY. Job loss and re-employment of cancer patients in Korean employees: a nationwide retrospective cohort study. J Clin Oncol. 2008;26(8):1302-9.

33. Noeres D, Park-Simon TW, Grabow J, Sperlich S, Koch-Giesselmann H, Jaunzeme J, Geyer S. Return to work after treatment for primary breast cancer over a 6-year period: results from a prospective study comparing patients with the general population. Support Care Cancer. 2013;21(7):1901-9.

34. Jun JK, Choi KS, Lee HY, Suh M, Park B, Song SH, Jung KW, Lee CW, Choi IJ, Park EC, et al. Effectiveness of the Korean National Cancer Screening Program in reducing gastric cancer mortality. Gastroenterology. 2017;152(6): 1319-1328 e1317.

\section{Submit your next manuscript to BioMed Central and we will help you at every step:}

- We accept pre-submission inquiries

- Our selector tool helps you to find the most relevant journal

- We provide round the clock customer support

- Convenient online submission

- Thorough peer review

- Inclusion in PubMed and all major indexing services

- Maximum visibility for your research

Submit your manuscript at www.biomedcentral.com/submit
) Biomed Central 